\title{
Cord blood Th2-related chemokine CCL22 levels associate with elevated total-IgE during preschool age
}

\author{
N V Folsgaard, B L K Chawes, K Bonnelykke, Maria Jenmalm and H Bisgaard
}

\section{Linköping University Post Print}

N.B.: When citing this work, cite the original article.

This is the authors' version of the following article:

N V Folsgaard, B L K Chawes, K Bonnelykke, Maria Jenmalm and H Bisgaard, Cord blood Th2-related chemokine CCL22 levels associate with elevated total-IgE during preschool age, 2012, Clinical and Experimental Allergy, (42), 11, 1596-1603.

which has been published in final form at:

http://dx.doi.org/10.1111/j.1365-2222.2012.04048.x

Copyright: Blackwell Publishing http://www.blackwellpublishing.com/

Postprint available at: Linköping University Electronic Press http://urn.kb.se/resolve?urn=urn:nbn:se:liu:diva- 85850 


\section{Cord Blood Th2-related Chemokine CCL22 Levels Associate with Elevated Total-IgE during Preschool Age}

Følsgaard NV, MD ${ }^{1}$, Chawes BL, MD, PhD ${ }^{1}$, Bønnelykke K, MD, $\mathrm{PhD}^{1}$, Jenmalm MC, $\mathrm{PhD}^{2}$, Bisgaard H, MD, DMsc ${ }^{1}$.

1. Copenhagen Prospective Studies on Asthma in Childhood; Copenhagen University Hospital, Gentofte, Denmark.

2. Department of Clinical and Experimental Medicine, Linköping University, Sweden

\section{Correspondence and request for reprints:}

Professor Hans Bisgaard

Copenhagen Prospective Studies on Asthma in Childhood

Copenhagen University Hospital; Gentofte

Ledreborg Allé 34

DK-2820 Gentofte

Copenhagen

Denmark

Tel: +4539777360

Fax: +45 39777129

E-mail: bisgaard@copsac.com

Website: www.copsac.com 
Source of funding and conflict of interest: COPSAC is funded by private and public research funds all listed on www.copsac.com. The Lundbeck Foundation; the Pharmacy Foundation of 1991; Augustinus Foundation; the Danish Medical Research Council and The Danish Pediatric Asthma Centre provided core support for COPSAC. This work was also supported by the Swedish Research Council (K2011-56X-21854-01-06), the Cancer and Allergy Association and the Olle Engkvist Foundation to MJ. The funding agencies did not have any role in study design, data collection and analysis, decision to publish, or preparation of the manuscript.

Word count: 2418

Tables: 3

Abbreviations:

C-C motif ligand 17 - CCL17, previously called Thymus and activation regulated chemokine (TARC)

C-C motif ligand 22 - CCL22, previously called Macrophage-derived chemokine (MDC)

COPSAC $_{2000}$ - Copenhagen Prospective study on Asthma in Childhood

C-X-C motif ligand chemokine 10 - CXCL10, previously called interferon gamma-induced protein $10 \mathrm{kDa}(\mathrm{IP}-10)$

C-X-C motif ligand chemokine 11 - CXCL11, previously called Interferon-inducible T-cell alpha chemoattractant (I-TAC)

IgE - Immunoglobulin E

Th- T helper cells 


\section{$\underline{\text { Abstract }}$}

Background: Early-life immune deviation is suspected in the inception of atopic disease.

Objective: We wished to investigate the association between cord blood chemokines and the subsequent development of atopic biomarkers and clinical end-points during the first 6 years of life.

Methods: The Th1-associated chemokines CXCL10 and CXCL11 and the Th2-associated chemokines CCL17 and CCL22 were assessed in cord blood of asymptomatic at-risk newborn children from the Copenhagen Prospective Study on Asthma in Childhood (COPSAC 2000 ) birth cohort and associated to the longitudinal development of biomarkers and clinical end-points of asthma, eczema and allergic rhinitis during the first 6 years of life.

Result: Cord blood CCL22 levels were significantly associated to total IgE levels measured at 4 time-points during the first 6 years of life; overall odds ratio, 1.54 [CI, 1.25-1.89; $P<0.0001]$. CXCL10 and CXCL11 were not associated to development of any atopic disorders or biomarkers.

Conclusion and clinical relevance: High cord blood levels of the Th2 related chemokine CCL22 were significantly associated to high total IgE levels during the first 6 years of life, but not to specific sensitization, asthma, eczema or allergic rhinitis. This suggests an inborn skewing of the immune system in healthy newborns developing elevated total IgE later in life. 


\section{INTRODUCTION}

The "atopic diseases" asthma, eczema and allergic rhinitis origin early in life, presumably as a result of a Th2 skewing of the immune system [1,2]. It is important to understand early-life immune mechanisms responsible for the inception of atopic disease in order to unravel disease pathogenesis towards preventive measures and possibly customized therapies.

Cord blood is easily accessible at birth and provides a unique opportunity to investigate the immunity of the new-born prior to disease onset. Circulating levels of Th1 and Th2 cytokines are difficult to measure in cord blood due to low levels close to the detection limit of the currently available assays [3]. Challenge models generate an exaggerated and possibly unphysiological response. Chemokines are simple to measure with current technology and are equally robust markers of Th1/Th2 immunity[4-8] in manifest atopic disorders. However, little is known about cord blood Th1-and Th2-related chemokine levels [4,9]. We hypothesized that Th2 related chemokines in the cord blood are associated to the development of atopic disease and biomarkers during preschool age.

The aim of this work was to investigate the association between the cord blood chemokines Thymus and activation regulated chemokine, TARC (CCL17), Macrophage-derived chemokine, MDC (CCL22), interferon gamma-induced protein 10 kDa, IP-10 (CXCL10) and Interferoninducible T-cell alpha chemoattractant, I-TAC (CXCL11) in asymptomatic at-risk newborn children from the Copenhagen Prospective Study on Asthma in Childhood (COPSAC 2000 ) birth cohort in relation to the subsequent development of atopic biomarkers and clinical end-points during the first 6 years of life. 


\section{METHODS}

The study is reported in accordance with the STROBE guidelines for observational studies [10].

\section{Study population}

Participants comprised children from the COPSAC 2000 cohort of 411 children born of mothers with doctor-verified asthma, the recruitment of whom was previously described in detail [11]. The pregnant women visited the COPSAC research centre during pregnancy for information on the study procedures. Key exclusion criteria were gestational age $<36$ weeks, severe congenital abnormality, neonatal mechanical ventilation or symptoms of lower airway infection before one month of age. Consenting mothers brought their one-month-old child to the research clinic and subsequently attended the clinic at six-monthly intervals and immediately upon onset of any allergy-, respiratory- or skin-related symptom until age 7 years.

\section{Ethics}

The study was conducted in accordance with the guiding principles of the Declaration of Helsinki and approved by the Ethics Committee for Copenhagen (KF 02-118/98) and the Danish Data Protection Agency (1998-1200-359). Data validity was assured by compliance with Good Clinical Practice guidelines and quality control procedures.

\section{Cord blood collection and analyses}

The midwives received written instructions on the collection of cord blood by needle puncture from the umbilical cord vein: $14 \mathrm{ml}$ cord blood was collected $(7 \mathrm{ml}$ in an EDTA tube and $7 \mathrm{ml}$ whole blood) and subsequently send to the COPSAC research unit, where the blood was centrifuged for $10 \mathrm{~min}$ at $4300 \mathrm{rpm}$ to separate serum and plasma, and thereafter frozen at $-80^{\circ} \mathrm{C}$ until analysis at the Department of Clinical and Experimental Medicine, Linköping 
University, Sweden. The chemokines CXCL10, CXCL11, CCL17 and CCL22 were analysed with an in-house multiplexed Luminex assay, as described in detail previously [4]. The limit of detection was $6 \mathrm{pg} / \mathrm{ml}$ for CXCL10, $28 \mathrm{pg} / \mathrm{ml}$ for CXCL11, and $2 \mathrm{pg} / \mathrm{ml}$ for CCL17 and CCL22. All samples were analysed in duplicates and the sample was re-analysed if the coefficient of variation $(\mathrm{CV})$ was $>15 \%$.

\section{Atopic biomarkers}

Blood was collected from the children at ages 6 months, 18 months, 4 years and 6 years during visits at the research unit. All samples were stored at $-80^{\circ} \mathrm{C}$ until analysis.

Total IgE levels were measured at age 6 months, 18 months, 4 years and 6 years by ImmunoCAP (Pharmacia Diagnostics AB, Uppsala, Sweden) with a detection limit of $2 \mathrm{kU} / \mathrm{l}$. Specific IgE levels against 15 common inhalant and food allergens (cat, dog, horse, birch, timothy grass, mugwort, house dust mites, moulds, hen's egg, cow's milk, fish, wheat, peanut, soybean, or shrimp) were measured at age 6 months, 18 months, 4 years and 6 years by ImmunoCAP (Pharmacia Diagnostics AB, Uppsala, Sweden) [12,13].

Skin Prick Test was performed at 6 months, 18 months, 4 years and 6 years against 18 common inhalant and food allergens (birch, timothy grass, mugwort, horse, dog, cat, house dust mites, moulds, hen's egg, cow's milk, fisk, wheat, rye, oat, peanut, soyabean, beef and pork) with standard allergen solutions from ALK-Abelló ${ }^{\circledR}$ and additionally with pasteurised, fresh products for cow's milk and hen's egg.

Allergic sensitization was defined as specific IgE $\geq 0.35 \mathrm{kU} / \mathrm{l}[12,13]$ for any of the tested allergens and/or a positive skin prick test defined as a wheal $\geq 2 \mathrm{~mm}$ at 6 and 18 months or $\geq$ $3 \mathrm{~mm}$ at 4 or 6 years. Allergic sensitization was analysed as a dichotomized measurement. 
Blood eosinophil count $\left(10^{9}\right.$ cells/l) was assessed at age 6 months, 18 months, 4 years and 6 years.

Nasal eosinophilia was examined by nasal scrapings in the child's $6^{\text {th }}$ year of life and rated according to Meltzer's semi-quantitative scale[14] as previously detailed [15].

\section{Investigator-diagnosed Clinical End-points}

Allergic rhinitis was diagnosed at age 6 by the COPSAC doctors, based on parent interviews on symptom history in the child's $6^{\text {th }}$ year of life [15]. Rhinitis was defined as troublesome sneezing or blocked or runny nose in the past 12 months in periods without accompanying virus symptoms [16]. Allergic rhinitis was diagnosed in children sensitized to inhaled allergens of relevance to the symptomatic periods.

Asthma at age 7 years was diagnosed as previously detailed,[17,18] and was based on a history of recurrent wheeze; symptom character judged by the study physicians to be typical of asthma; response to trials of inhaled corticosteroids; and relapse when stopping treatment.

Eczema during the first 6 years of life was diagnosed using the Hanifin-Rajka criteria as previously detailed [19]. Skin lesions were described at both scheduled and acute visits according to pre-defined morphology and localization.

\section{Statistical Analysis}

We investigated the association between cord blood levels of the chemokines CXCL10, CXCL11, CCL17, CCL22 and the Th2/Th1 ratios CCL22/CXCL10, CCL17/CXCL10, CCL22/CXCL11, CCL17/CXCL11, and the development of atopic biomarkers and atopic clinical end-points during the first 6 years of life. Models using general estimating equations (GEE; PROC GENMOD in SAS version 9.1) were applied to compute the overall odds ratio for allergic 
sensitization, blood eosinophil count and total-IgE using compiled data from all four measuring points ( 6 months, 18 months, 4 years and 6 years). Logistic regression was used to calculate odds ratios of the cross-sectional end-points allergic rhinitis, nasal eosinophilia, and asthma. Hazard ratios of recurrent wheeze and eczema at age 0-1 year and 0-6 year were calculated by Cox regression. Age at onset was modelled as a function of chemokine levels and ratios; the children were retained in the analysis from birth until age at onset of disease, dropout, or age at end of the observation period (i.e. 1 year for 0-1 year), whichever first. Levels of chemokines, total IgE, and blood eosinophilia were log-transformed prior to analysis.

Results are reported with 95\% CI in brackets. Robustness of results was investigated by adjusting for multiple testing according to the method by Bonferoni correction for control of false discovery rate. All analyses were done in SAS version 9.1 for Windows (SAS Institute, Inc., Cary, NC). 


\section{RESULTS:}

\section{Baseline}

Cord blood samples were available for analyses from 223 of the 411 children from the COPSAC $_{2000}$ cohort. Children from low-income families were significantly less likely to have cord blood sampled $[P$-value $=0.008]$, whereas there were no differences between children with and without cord blood samples with respects to ethnicity, exposure to tobacco, alcohol and maternal antibiotic use during $3^{\text {rd }}$ trimester, mode of delivery, gestational age, gender or anthroprometrics (Table 1).

Levels of chemokines, total-IgE, blood eosinophil count and frequency of nasal eosinophilia, allergic rhinitis, asthma, eczema and allergic sensitization in the study group are outlined in Table 2.

\section{Association between cord blood chemokine levels and atopic biomarkers}

Total-IgE: Cord blood CCL22 levels were significantly associated to total IgE levels at 6 months, 18 months, 4 years and 6 years (GEE model including all 4 measuring points): odds ratio, 1.54 [CI, 1.25-1.89; $P<0.0001]$. In addition, the Th2/Th1 ratios were also associated to Total IgE levels: CCL22/CXCL11: odds ratio, 1.31 [CI, 1.13-1.51; $P=0.0002]$ and CCL22/CXCL10 odds ratio, 1.22 [CI, 1.03-1.43; $P=0.02]$. However, the CCL22/CXCL10 ratio did not pass the Bonferroni threshold for significance (Table 3). There was no association between CCL17, CXCL11 or CXCL10 and Total IgE levels. Figure 1 shows the individualized association between cord blood CCL22 and total IgE at each measured time-point.

Specific IgE: No association was found between specific IgE and any cord blood chemokine levels (Table 3). 
Blood eosinophil count: Cord blood CCL22 and CXCL11 levels were associated with development of blood eosinophilia in the overall GEE model: Odds ratio, 1.15 [CI, 1.00-1.32; $P=0.05]$ and odds ratio, 1.09 [CI, 1.00-1.20; $\mathrm{P}=0.05]$, respectively. However, this was not significant after correction for multiple testing. There was no association between CCL22/CXCL10, CCL22/CXCL11, CCL17/CXCL10, CCL17/CXCL11 ratios, CXCL10 or CCL17, and blood eosinophilia (Table 3).

Nasal eosinophilia at age 6 years was not associated with any of the tested chemokines or Th2/Th1 ratios (Table E1 online).

\section{Association between cord blood chemokine levels and Investigator-diagnosed Clinical End-points}

No association was found between levels or ratios of any of the tested cord blood chemokines and development of eczema, asthma, troublesome lung symptoms or allergic rhinitis during the first 6 years of life (Tables E2 to E5 online). 


\section{DISCUSSION:}

\section{Principle findings}

Cord blood levels of the Th2 related chemokine CCL22 and Th2/Th1 chemokine ratios in healthy newborns from the Danish $\mathrm{COPSAC}_{2000}$ birth cohort of asthmatic mothers were significantly associated with total IgE levels during the first 6 years of life. This suggests an inborn/intrauterine Th2 skewing of the immune system in children subsequently developing high levels of total IgE.

\section{Strengths and limitations}

The major strength of this study is the 6-year longitudinal, stringent and uniform clinical follow-up of a birth cohort. COPSAC is a single-center study where the COPSAC doctors act as general practitioners for the children, diagnosing and treating all airway-, allergy- and skinrelated symptoms according to predefined algorithms thus assuring consistency in diagnoses and reducing the risk of misclassification.

In addition, the atopic biomarkers; blood eosinophil count, specific- and total-IgE were assessed repeatedly at 4 time points till 6 years of age, increasing the statistical power to detect true associations in GEE models accounting for repeated within subject measurements.

A further strength of the study is the sensitivity of the chemokine assays allowing assessment of chemokine levels in all available cord blood samples without stimulation, thus avoiding excessive un-physiological responses accompanying challenge models. Circulating Th1- and Th2-associated chemokine levels can be used as markers for the Th1/Th2 balance[48] making immune-regulatory chemokines potential biomarkers of current and future disease [20]. Th1 responses increase the levels of CXCR3 ligands CXCL10 and CXCL11, while Th2 responses enhance the levels of CCR4 ligands CCL17 and CCL22.[21,22] CXCR3 is 
preferentially expressed on Th1 cells and CCR4 on Th2 cells, thus further amplifying Th1 and Th2 immunity, respectively [22].

Finally, the large cord blood sample size of 223 samples increases the validity of the data.

Cord blood biomarkers may be biased by transfer from maternal blood. This has been demonstrated for specific and total IgE where maternal levels are often 1000 times higher than cord blood levels and even minimal amount of maternal blood may significantly affect cord blood levels $[23,24]$. Such bias from maternal transfer seems not to be an issue for cord blood chemokines that are often found in higher level in cord blood than maternal blood.

A limitation of our study is the high-risk nature of the COPSAC 2000 cohort where all mothers have a history of asthma which requires replication in an unselected population. However, the analyses were based on within subject associations between cord blood chemokine levels and the subsequent development of atopic disease and atopic biomarkers unlikely to be affected by the increased risk of atopic diseases. This is supported by a previous study where elevated cord blood CCL22 levels preceded development of sensitisation independent of atopic heredity [9].

A further limitation is that cord blood samples were only available from half of the cohort. However, the selected cohort was representative of the main cohort for the majority of population characteristics.

\section{Interpretation}

Elevated cord blood levels of the CCL22 chemokine preceding development of raised total IgE during the first 6 years of life suggests a triggering role of CCL22 in the inception of elevated total IgE in children on an atopic trajectory. The mechanism responsible for the linkage 
between elevated CCL22 and raised total IgE is unknown, though CCL22 is described to play a central role in enhancing the Th2 responses. Thus, our data support the general hypothesis of an early life Th2 skewing of the immune response [1,3].

Cord blood CCL22 levels have previously been proposed as a predictor of elevated IgE levels and clinically manifest allergy development [6,25]. However, only a few others have studied un-stimulated cord blood chemokines. Our findings are supported by a previous report from 56 children where cord blood CCL22 was associated with elevated IgE levels at age 6 [9]. We found no association between cord blood chemokine levels and development of atopic symptoms of asthma, rhinitis or eczema. It is possible that CCL22 is involved in a specific immunological mechanism only causing elevated total IgE but not specific sensitization or disease. Cord blood CCL17 and CCL22 have been associated to atopic dermatitis and asthma development in cohorts of mixed atopic and non-atopic parental predisposition [9,26]. Since this study is the largest to date, it is possible that previously reported association to atopic disease were the result of a type 1 error. The discrepancy between these findings and our data might also be due to the high-risk nature of the $\mathrm{COPSAC}_{2000}$ cohort.

The mechanism behind elevated cord blood CCL22 remains unclear. However, such pronounced Th2/Th1 imbalance in the newborn may be driven by genetic variants and/or caused by unknown intrauterine environmental triggers impacting the fetal development.

We have previously shown that urine eosinophil protein $\mathrm{X}$ in neonates precedes development of allergic sensitization and eczema,[27] and that raised exhaled nitric oxide in neonates associates with development of early transient wheeze [28]. Importantly, these findings and the current study supports the concept of early immunological programming of immune function plays an essential role in the skewing of the immune response. Together such finger- 
prints of atopic disease development in new-borns may contribute to construction of clinically feasible prediction models in the future.

\section{Conclusion:}

High cord blood levels of the Th2 related chemokine CCL22 were significantly associated to high total IgE levels during the first 6 years of life. This suggests an inborn Th2 skewing of the immune system in healthy newborns developing elevated total IgE later in life.

\section{Authors Contribution}

The guarantor of the study is HB who has been responsible for the integrity of the work as a whole, from conception and design to acquisition of data, analysis and interpretation of data and writing of the manuscript. NVF contributed to data analyses, statistical analysis, interpretation and writing of the manuscript.

MJ preformed analysis of chemokines, data interpretation and writing of the manuscript. BLC and KB contributed to data analyses, interpretation and writing of the manuscript. All authors made important intellectual contributions and critical final revision of the manuscript.

\section{Acknowledgement}

The authors wish to thank the children and parents participating in the COPSAC cohort as well as the COPSAC study team. 
Table 1: Baseline demographics. P-values were calculated by chi-square test.

\begin{tabular}{|c|c|c|c|c|}
\hline \multirow[b]{2}{*}{ Baseline demografics } & \multirow{2}{*}{$\begin{array}{c}\text { Entire COPSAC } \\
\text { cohort } \\
\mathbf{N}=\mathbf{4 1 1}\end{array}$} & \multicolumn{2}{|c|}{ Cord blood } & \multirow[b]{2}{*}{$P$-value } \\
\hline & & $\begin{array}{c}\text { Collected } \\
\mathrm{N}=223\end{array}$ & $\begin{array}{c}\text { Not collected } \\
\quad \mathrm{N}=188\end{array}$ & \\
\hline Sex male & $203(49.4 \%)$ & $112(55.2 \%)$ & $91(44.8 \%)$ & 0.71 \\
\hline Birth length* & $133(32.0 \%)$ & $75(33.6 \%)$ & $58(30.9 \%)$ & 0.16 \\
\hline Birth weight** & $129(31.4 \%)$ & $69(30.9 \%)$ & $60(31.9 \%)$ & 0.60 \\
\hline Mode of delivery*** & $85(20.7 \%)$ & $43(19.3 \%)$ & $42(22.3 \%)$ & 0.53 \\
\hline Occupation & & & & 0.15 \\
\hline Non-professional & $128(33.5 \%)$ & $69(33.7 \%)$ & $59(33.3 \%)$ & \\
\hline Professional & $174(45.6 \%)$ & $100(48.8 \%)$ & $74(41.8 \%)$ & \\
\hline Student & $42(10.9 \%)$ & $22(10.7 \%)$ & $20(11.3 \%)$ & \\
\hline Unemployed & $14(6.8 \%)$ & $14(6.8 \%)$ & $24(13.6 \%)$ & \\
\hline Household income & & & & 0.008 \\
\hline Low & $112(29.2 \%)$ & $47(22.8 \%)$ & $65(36.5 \%)$ & \\
\hline Average & $182(47.4 \%)$ & $110(53.4 \%)$ & $72(40.5 \%)$ & \\
\hline High & $90(23.4 \%)$ & $49(23.8 \%)$ & $41(23.0 \%)$ & \\
\hline \multicolumn{5}{|l|}{ Expositions } \\
\hline Smoking during 3. trimester & $63(15.3 \%)$ & $36(16.1 \%)$ & $27(14.4 \%)$ & 0.61 \\
\hline Alcohol during 3 trimester & $73(17.8 \%)$ & $40(17.9 \%)$ & $33(17.6 \%)$ & 0.91 \\
\hline Antibiotics 3 trimester & $125(30.4 \%)$ & $67(53.6 \%)$ & $58(46.4 \%)$ & 0.85 \\
\hline
\end{tabular}

* lowest birth length tertile

** lowest birth weight tertile

*** Caesarian sectio 
Table 2: Baseline levels of chemokines and endpoints

\begin{tabular}{|c|c|c|c|c|c|}
\hline & \multicolumn{5}{|c|}{ Age-Point } \\
\hline Variable & $\begin{array}{l}\text { Birth } \\
\text { (Cord blood) }\end{array}$ & 6 Months & 18 Months & 4 Year & 6 Year \\
\hline $\begin{array}{l}\text { CCL22 pg/ml; median } \\
\text { (range) }\end{array}$ & $\begin{array}{l}441 \\
(57-3581)\end{array}$ & & & & \\
\hline $\begin{array}{l}\text { CCL17 pg/ml; median } \\
\text { (range) }\end{array}$ & $\begin{array}{l}211 \\
(8.6-3949)\end{array}$ & & & & \\
\hline $\begin{array}{l}\text { CXCL11 pg/ml; median } \\
\text { (range) }\end{array}$ & $\begin{array}{l}215 \\
(35-2657)\end{array}$ & & & & \\
\hline $\begin{array}{l}\text { CXCL10 pg/ml; median } \\
\text { (range) }\end{array}$ & $\begin{array}{l}35 \\
(6.4-294)\end{array}$ & & & & \\
\hline $\begin{array}{l}\text { Blood Eosinophil count }\left(\times 10^{9} / \mathrm{L}\right) \\
\text { median (range) }\end{array}$ & & $\begin{array}{l}0.27 \\
(0.06-1.45)\end{array}$ & $\begin{array}{l}0.21 \\
(0.04-1.19)\end{array}$ & $\begin{array}{l}0.24 \\
(0.01-3.0)\end{array}$ & $\begin{array}{l}0.32 \\
(0-3.5)\end{array}$ \\
\hline $\begin{array}{l}\text { Total-IgE (kU/L); } \\
\text { median (range) }\end{array}$ & & $4(0.13-71)$ & $7.7(0.03-90)$ & $27(0.13-71)$ & $46(1.9-1564)$ \\
\hline Allergic Sensitization $; \%$ (N) & & $6.3 \%(14)$ & $9.3 \%(21)$ & $19 \%(42)$ & $25 \%(56)$ \\
\hline Sensitization ever; $\%(\mathrm{~N})$ & & & & & $36 \%(77)$ \\
\hline Allergic Rhinitis; 6yr; \%(N) & & & & & $8 \%(13)$ \\
\hline Nasal Eosinophilia $^{\dagger} 6$ yr; \% (N) & & & & & $5 \%(8)$ \\
\hline Asthma 7 yr; \% (N) & & & & & $17 \%(32)$ \\
\hline
\end{tabular}

*Allergic Sensitization=any sensitization for cat, dog, horse, birch, timothy grass, mugwort, house dust mites, moulds, hen's egg, cow's milk, fish, wheat, peanut, soybean, or shrimp.

†Nasal eosinophilia ( $>+1$ on Meltzer's semi-quantitative scale) 
Table 3: Association between cord blood chemokine levels and allergic sensitization, blood eosinophil count and total-IgE. Results are based on GEE analysis; According to Bonferoni correction for multiple testing, only P-values $<0.006$ are considered significant.

\begin{tabular}{|c|c|c|c|c|c|c|}
\hline \multirow[b]{2}{*}{ Chemokines } & \multicolumn{2}{|c|}{ Allergic Sensitization* } & \multicolumn{2}{|c|}{ Blood eosinophil count } & \multicolumn{2}{|l|}{ Total-IgE } \\
\hline & $\begin{array}{l}\text { Odds ratio } \\
{[95 \% \mathrm{CI}]}\end{array}$ & $P$-value & $\begin{array}{l}\text { Odds ratio } \\
{[95 \% \mathrm{CI}]}\end{array}$ & P-value & $\begin{array}{l}\text { Odds ratio } \\
{[95 \% \mathrm{CI}]}\end{array}$ & P-value \\
\hline CCL22 & $\begin{array}{l}1,35 \\
{[0,94-1,95]}\end{array}$ & .10 & $\begin{array}{l}1,15 \\
{[1,00-1,32]}\end{array}$ & .05 & $\begin{array}{l}1.54 \\
{[1.25-1.89]}\end{array}$ & $<.0001$ \\
\hline CCL22/CXCL10 & $\begin{array}{l}1,08 \\
{[0,80-1,45]}\end{array}$ & .62 & $\begin{array}{l}1,07 \\
{[0,97-1,18]}\end{array}$ & .16 & $\begin{array}{l}1.22 \\
{[1.03-1.43]}\end{array}$ & .02 \\
\hline CCL22/CXCL11 & $\begin{array}{l}1,23 \\
{[0,90-1,68]}\end{array}$ & .19 & $\begin{array}{l}0,99 \\
{[0,91-1,09]}\end{array}$ & .93 & $\begin{array}{l}1.31 \\
{[1.13-1,51]}\end{array}$ & .0002 \\
\hline CXCL10 & $\begin{array}{l}1,15 \\
{[0,76-1,72]}\end{array}$ & .51 & $\begin{array}{l}1,01 \\
{[0,90-1,13]}\end{array}$ & .83 & $\begin{array}{l}1,05 \\
{[0,83-1,32]}\end{array}$ & .67 \\
\hline CXCL11 & $\begin{array}{l}0,94 \\
{[0,66-1,33]}\end{array}$ & .71 & $\begin{array}{l}1,09 \\
{[1,001-1,2]}\end{array}$ & .05 & $\begin{array}{l}0,93 \\
{[0,80-1,10]}\end{array}$ & .43 \\
\hline CCL17 & $\begin{array}{l}0,97 \\
{[0,76-1,24]}\end{array}$ & .82 & $\begin{array}{l}1,06 \\
{[0,98-1,13]}\end{array}$ & .13 & $\begin{array}{l}1,02 \\
{[0,90-1,15]}\end{array}$ & .75 \\
\hline CCL17/CXCL10 & $\begin{array}{l}0,95 \\
{[0,77-1,16]}\end{array}$ & .61 & $\begin{array}{l}1,03 \\
{[0,97-0,09]}\end{array}$ & .27 & $\begin{array}{l}1.00 \\
{[0,89-1,11]}\end{array}$ & .99 \\
\hline CCL17/CXCL11 & $\begin{array}{l}1,02 \\
{[0,72-1,44]}\end{array}$ & .91 & $\begin{array}{l}0,99 \\
{[0,90-1,10]}\end{array}$ & .96 & $\begin{array}{l}1,11 \\
0.93-1,34]\end{array}$ & .22 \\
\hline
\end{tabular}


Figure 1: Correlation between cord blood CCL22 and total IgE at 6 months, 18 months, 4 years and 6 years. All data are log transformed.
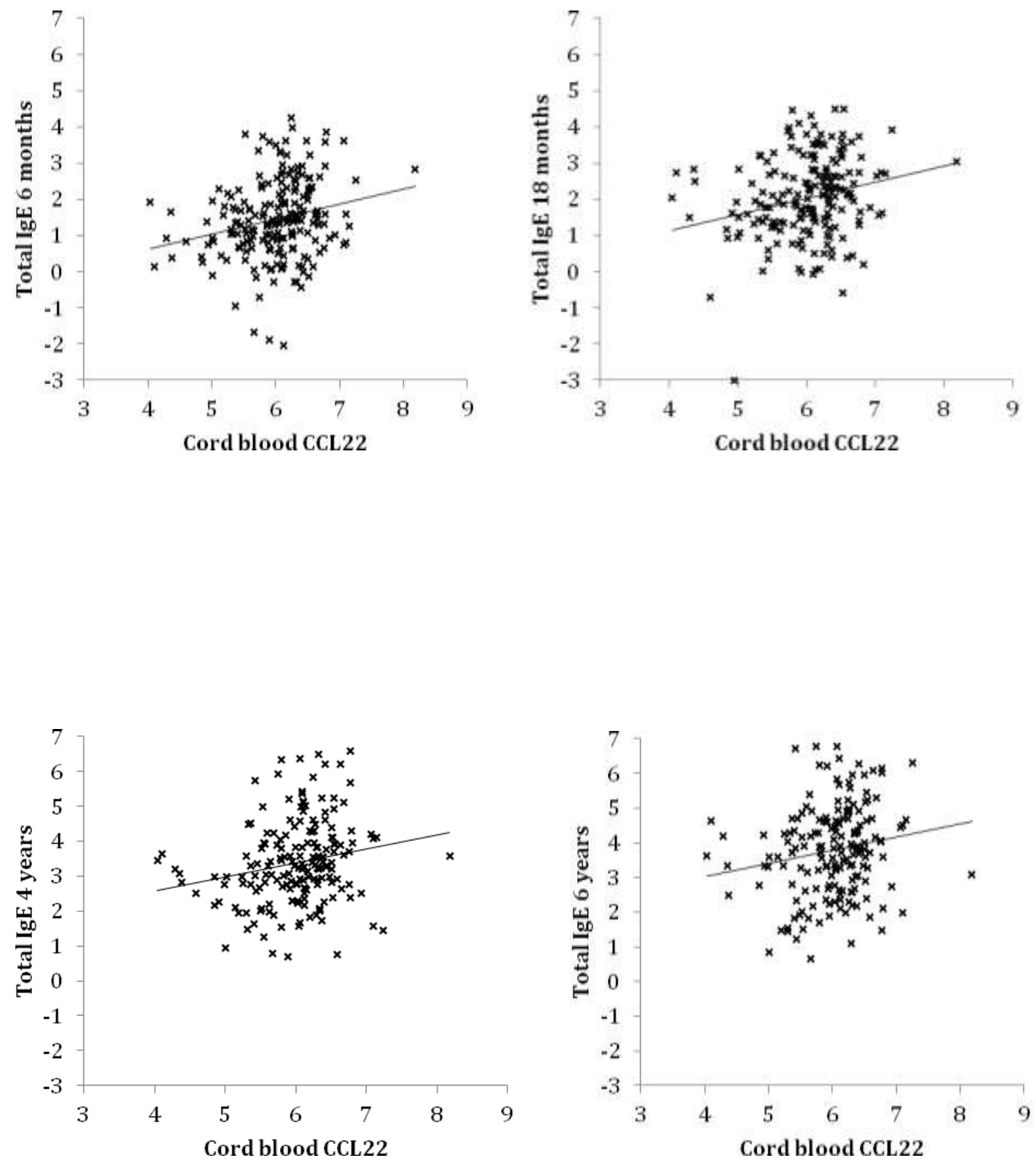


\section{Reference List}

1. Leung T-F, Ng P-C, Tam W-H, et al. Helper T-lymphocyte-related chemokines in healthy newborns. Pediatr. Res. 2004; 55:334-338.

2. Hawrylowicz C, Ryanna K. Asthma and allergy: The early beginnings. Nat Med 2010; $16: 274-275$.

3. Sandberg M, Frykman A, Ernerudh J, et al. Cord blood cytokines and chemokines and development of allergic disease. Pediatric Allergy and Immunology 2009; 20:519-527.

4. Abrahamsson TR, Sandberg Abelius M, Forsberg A, Björkstén B, Jenmalm MC. A Th1/Th2-associated chemokine imbalance during infancy in children developing eczema, wheeze and sensitization. Clin. Exp. Allergy 2011; 41:1729-1739.

5. Fujisawa T, Fujisawa R, Kato Y, et al. Presence of high contents of thymus and activation-regulated chemokine in platelets and elevated plasma levels of thymus and activation-regulated chemokine and macrophage-derived chemokine in patients with atopic dermatitis. Journal of Allergy and Clinical Immunology 2002; 110:139-146.

6. Jahnz-Rozyk K, Targowski T, Paluchowska E, Owczarek W, Kucharczyk A. Serum thymus and activation-regulated chemokine, macrophage-derived chemokine and eotaxin as markers of severity of atopic dermatitis. Allergy 2005; 60:685-688.

7. Aggarwal A, Agarwal S, Misra R. Chemokine and chemokine receptor analysis reveals elevated interferon-inducible protein-10 (IP)-10/CXCL10 levels and increased number of CCR5 + and CXCR3+ CD4 T cells in synovial fluid of patients with enthesitis-related arthritis (ERA). Clinical \& Experimental Immunology 2007; 148:515-519.

8. Stumpf C, Auer C, Yilmaz A, et al. Serum levels of the Th1 chemoattractant interferon-gamma-inducible protein (IP) 10 are elevated in patients with essential hypertension. Hypertens. Res. 2011; 34:484-488.

9. Abelius MS, Ernerudh J, Berg G, Matthiesen L, Nilsson LJ, Jenmalm MC. High Cord Blood Levels of the T-Helper 2-Associated Chemokines CCL17 and CCL22 Precede Allergy Development During the First 6 Years of Life. Pediatr. Res. 2011; 70:495-500.

10. von Elm E, Altman DG, Egger M, Pocock SJ, Gøtzsche PC, Vandenbroucke JP. The Strengthening the Reporting of Observational Studies in Epidemiology (STROBE) Statement: Guidelines for Reporting Observational Studies. PLoS Med 2007; 4.

11. Bisgaard H. The Copenhagen Prospective Study on Asthma in Childhood (COPSAC): design, rationale, and baseline data from a longitudinal birth cohort study. Ann. Allergy Asthma Immunol 2004; 93:381-389. 
12. Ballardini N, Nilsson C, Nilsson M, Lilja G. ImmunoCAP Phadiatop Infant--a new blood test for detecting IgE sensitisation in children at 2 years of age. Allergy 2006; 61:337343.

13. Wickman M, Ahlstedt S, Lilja G, van Hage Hamsten M. Quantification of IgE antibodies simplifies the classification of allergic diseases in 4-year-old children. A report from the prospective birth cohort study--BAMSE. Pediatr Allergy Immunol 2003; 14:441-447.

14. Howarth PH, Persson CGA, Meltzer EO, Jacobson MR, Durham SR, Silkoff PE. Objective monitoring of nasal airway inflammation in rhinitis. J. Allergy Clin. Immunol. 2005; 115:S414-441.

15. Chawes BLK, Kreiner-Møller E, Bisgaard H. Objective assessments of allergic and nonallergic rhinitis in young children. Allergy 2009; 64:1547-1553.

16. Braun-Fahrländer C, Wüthrich B, Gassner M, et al. Validation of a rhinitis symptom questionnaire (ISAAC core questions) in a population of Swiss school children visiting the school health services. SCARPOL-team. Swiss Study on Childhood Allergy and Respiratory Symptom with respect to Air Pollution and Climate. International Study of Asthma and Allergies in Childhood. Pediatr Allergy Immunol 1997; 8:75-82.

17. Bisgaard H, Hermansen MN, Buchvald F, et al. Childhood asthma after bacterial colonization of the airway in neonates. N. Engl. J. Med 2007; 357:1487-1495.

18. Bisgaard H, Hermansen MN, Loland L, Halkjaer LB, Buchvald F. Intermittent inhaled corticosteroids in infants with episodic wheezing. N. Engl. J. Med 2006; 354:19982005.

19. Halkjaer LB, Loland L, Buchvald FF, et al. Development of Atopic Dermatitis During the First 3 Years of Life: The Copenhagen Prospective Study on Asthma in Childhood Cohort Study in High-Risk Children. Arch Dermatol 2006; 142:561-566.

20. Hayglass KT. The quest for predictive immune biomarkers. Clin. Exp. Allergy 2011; 41:1656-1659.

21. Mantovani A, Sica A, Sozzani S, Allavena P, Vecchi A, Locati M. The chemokine system in diverse forms of macrophage activation and polarization. Trends in Immunology 2004; 25:677-686.

22. Pease JE, Williams TJ. Chemokines and their receptors in allergic disease. Journal of Allergy and Clinical Immunology 2006; 118:305-318.

23. Bønnelykke K, Pipper CB, Bisgaard H. Sensitization does not develop in utero. J. Allergy Clin. Immunol 2008; 121:646-651. 
24. Bønnelykke K, Pipper CB, Bisgaard H. Transfer of maternal IgE can be a common cause of increased IgE levels in cord blood. J. Allergy Clin. Immunol 2010; 126:657-663.

25. Nakazato J, Kishida M, Kuroiwa R, Fujiwara J, Shimoda M, Shinomiya N. Serum levels of Th2 chemokines, CCL17, CCL22, and CCL27, were the important markers of severity in infantile atopic dermatitis. Pediatr Allergy Immunol 2008; 19:605-613.

26. Miyahara H, Okazaki N, Nagakura T, Korematsu S, Izumi T. Elevated umbilical cord serum TARC/CCL17 levels predict the development of atopic dermatitis in infancy. Clinical \& Experimental Allergy 2011; 41:186-191.

27. Chawes BLK, Bønnelykke K, Bisgaard H. Elevated Eosinophil Protein X in Urine from Healthy Neonates Precedes Development of Atopy in the First 6 Years of Life. Am J Respir Crit Care Med 2011; Available at: http://www.ncbi.nlm.nih.gov/pubmed/21680952. Accessed 28 July 2011.

28. Chawes BLK, Buchvald F, Bischoff AL, et al. Elevated exhaled nitric oxide in highrisk neonates precedes transient early but not persistent wheeze. Am. J. Respir. Crit. Care Med 2010; $182: 138-142$. 